\title{
Structural Behavior of HFRP-Steel Double-Lap Joints with FRP Bolts
}

\author{
Omnia AbouEl-Hamd ${ }^{1}$, Amr Sweedan ${ }^{1}$, Khaled El-Sawy ${ }^{2}$ \\ ${ }^{1}$ United Arab Emirates University \\ P.O. Box 15551, Al-Ain, UAE \\ 200834604@uaeu.ac.ae; amr.sweedan@uaeu.ac.ae \\ ${ }^{2}$ Effat University \\ P.O. Box 34689, Jeddah, KSA \\ khelsawy@effatuniversity.edu.sa
}

\begin{abstract}
Fiber reinforced polymers (FRP) have been recently used in retrofitting and strengthening of existing steel structures. Pervious researches indicated that bonding FRP composites to steel elements is associated with undesirable brittle failure of the adhesive at the FRP-steel interface. An emerging strengthening technique, which involves attaching hybrid fiber reinforced polymer (HFRP) composites to steel elements using steel bolts, has proven its efficiency in rehabilitating steel structures. This study investigates the structural behavior of HFRP-steel joints with FRP bolts. An experimental program was conducted on twenty double-lap HFRP-steel joints with different bolt diameters and sheared edge distances. The findings revealed insignificant effect of the sheared edge distance on the joint response. Increasing the bolt diameter enhanced the load carrying capacity of the bolted joints significantly. Experimental outcomes suggested using FRP bolts with $13 \mathrm{~mm}$ diameter to connect the HFRP laminates to steel plates while maintaining a sheared edge distance that is three times the bolt-hole diameter. For the particular configurations tested in this study, a simplified nonlinear load-slip model was developed to describe the interfacial behavior of the HFRP-steel joints formed using FRP bolts. The model was then compared to a previously developed load-slip relationship for HFRP-steel joints that use steel bolts.
\end{abstract}

Keywords: Hybrid fiber reinforced polymers (HFRP), bolted joints, FRP bolts, edge distance, load-slip model

\section{Introduction}

Over the last two decades, fiber reinforced polymers (FRP) have been widely used in retrofitting steel structures due to their marvelous properties of corrosion resistivity, lightweight, high strength-to-weight ratio and ease of handling. A common technique of strengthening steel structures involves bonding FRP composites to targeted steel elements. Several researchers studied the behavior of steel beams strengthened with FRP laminates that are externally bonded to the tension flange of the strengthened beams to enhance their flexural capacity [1- 3]. A comprehensive review on steel beams retrofitted with bonded FRP composites indicated that the failure of bonded FRP-steel joints significantly depends on the adhesive properties and thicknesses [4]. Although bonded FRP-steel systems proved effectiveness in strengthening steel members, steel beams strengthened with externally bonded FRP strips were found to fail in a brittle mechanism due to debonding at the steel-FRP interface. In order to overcome the unfavorable brittle failure of bonded FRP composites, few researchers investigated the effectiveness of strengthening steel elements by bolting FRP composites. An experimental study was conducted to investigate the behavior of double-lap joints of steel splices bolted to hybrid CFRP-GFRP (HFRP) laminates [5]. The HFRP laminates were connected to the splices plates using steel bolts of $10 \mathrm{~mm}$ diameter. Analysis of the resulted load-displacement curves of the bolted joints implied that failure took place due to combined bearing and bending of the bolts. The study also examined the effect of end-distance on the failure loads and failure modes of the HFRP-steel joints. The use of end-distance that is four-times the bolt diameter was suggested to fully utilize the capacity of the bolted joints with maintaining ductile bearing failure.

In 2013, an experimental study was conducted to examine the effect of sheared and rolled edge distances and bolts' spacing on the behavior of FRP-steel joints [6]. Tested double-lap joints composed of hybrid CFRP-GFRP laminates that were bolted to steel plates using $6 \mathrm{~mm}$ galvanized steel bolts. Examined joints experienced combination of failure mechanisms including: bearing at the bolts-FRP interface, followed by bending in bolts and folding of washers and finally tear out of the FRP laminates. All specimens failed in a ductile manner verifying the ability of bolted systems to overcome 
the undesirable brittle failure of bonded FRP-steel systems. The experimental findings recommended the use of sheared edge distance that is six to seven times the hole-diameter for better ductility and carrying capacity of the joints. Meanwhile, the influence of rolled edge distance on the joint capacity was proven insignificant. Spacing between bolts had no significant effect on the failure mode of the joints for the selected range of spacing of $100 \mathrm{~mm}$ to $168 \mathrm{~mm}$ that was considered in the study. The experimental outcomes were used to develop a load-slip model that presents the interfacial behavior of the bolted FRP-steel joint. The developed load-slip model was further used to simulate the behavior of steel beams strengthened with FRP laminates that are bolted to the bottom flange [7]. Material and geometrical nonlinearities were considered in the simulation along with the relative slip at the FRP-steel interface. Resulted finite element predictions revealed a ductile behavior of the strengthened beams.

An extensive experimental investigation of the behavior of full-scale steel beams strengthened with bolted FRP composites was recently conducted [8]. In this study, UB203 $\times 102 \times 23$ steel beams were strengthened using HFRP laminates that were bolted to the bottom flange of the beams using $6 \mathrm{~mm}$ diameter galvanized steel bolts. The experimental program examined the influence of various lengths and thicknesses of the HFRP laminates on the response of strengthened beams. The experimental results implied that increasing the length of the bolted HFRP laminates enhanced both yield and ultimate loads of the strengthened beams by up to $6.4 \%$ and $19.4 \%$, respectively. Moreover, doubling the thickness of the HFRP laminates, while maintaining sufficient number of bolts, improved the yield and ultimate load carrying capacities of the beams by $9.1 \%$ and $30.6 \%$, respectively.

Despite the proved efficiency of the bolted FRP-steel system, no one attempted to investigate the effect of using nonmetallic bolts to overcome the potential corrosion of the steel components of the fastening system. Meanwhile, few researches were reported for work done on the use of FRP bolts to connect FRP components together. An experimental investigation was carried out to study the effect of using GFRP and steel bolts on the strength of composite-composite double lap joints [9]. It was noted that GFRP bolters reduced the capacity of the composite joints since they were weaker than the connected composite plates. On the contrary, the failure of joints formed using steel bolts was governed by the mechanical properties of the composite laminates. Another experimental study focused on exploring the use of composite bolts made of carbon-reinforced polymers on the mechanical behavior of CFRP-CFRP joints [10]. The behavior of joints with composite bolts was compared to that of joints connected using titanium bolts under static tensile loading. A constant bolt diameter of $6 \mathrm{~mm}$ was maintained throughout the investigation for all types of bolts. Experimental results showed better load carrying capacity for joints with titanium bolts than those with composite bolts. Joints formed using titanium bolts failed by sudden post peak net-section failure. The load-displacement curve for joint with composite bolts showed two failure modes. Fracture of the composite bolts was the dominant failure mode, followed by late bearing damage resulted from the left fractured pieces in the bolt-hole which created a pin loading set-up. Joints with the same configurations were tested under fatigue loading [11]. The main difference in the behavior of the joints was the observed failure modes where all joints failed in bolt fracture regardless of their type.

The remarkable properties of the FRP bolts, including their corrosion resistivity, lightweight, low conductivity and resistivity to UV degradation qualified them to replace the steel bolts commonly used in bolted strengthening systems. The current study was motivated by the potential efficiency of using bolted HFRP laminates in strengthening steel members. The paper reports on the outcomes of an experimental program that was carried out to explore the structural behavior of HFRP-steel joints formed using FRP bolts. The study also examined the effect of sheared edge distance and bolt diameter on the performance and load capacity of tested joints. A simplified nonlinear load-slip relationship was established to simulate the interfacial behavior of the tested joint. Finally, a comparison was presented to highlight the difference in structural response of HFRP-steel joints that use FRP bolts and those that are formed using galvanized steel bolts.

\section{Experimental Program}

The experimental program involved testing several configurations of double-lap HFRP-steel joints with FRP bolts. Test specimens were designed to explore the effect of sheared edge distance and bolt diameter on the performance of the bolted joints. Hybrid CFRP-GFRP (HFRP) laminates with $3.175 \mathrm{~mm}$ thickness and $101.6 \mathrm{~mm}$ width were connected to 10 $\mathrm{mm}$ thick steel plates using FRP bolts. The used steel plates had yield strength of $300 \mathrm{MPa}$, tensile strength of $460 \mathrm{MPa}$ and a modulus of elasticity of $200 \mathrm{GPa}$. Both HFRP laminates and FRP bolts are manufactured by STRONGWELL ${ }^{\circledR}$. The average tensile strength and elastic modulus of the HFRP laminates are $852 \mathrm{MPa}$, and $62.19 \mathrm{GPa}$, respectively. Meanwhile, FRP bolts had average ultimate tensile and shear strength values of $68 \mathrm{MPa}$ and $91 \mathrm{MPa}$, respectively, as provided by the manufacturer. Each bolt is composed of fiberglass stud, washer and nut whereas the washer is readily attached to the nut as 
shown in Fig. 1. The experimental program adopted two sizes of the FRP bolts in order to examine the effect of bolt diameter on the failure mode and response of the bolted joints. FRP bolts of $10 \mathrm{~mm}$ and $13 \mathrm{~mm}$ nominal diameters were used with a constant length of $120 \mathrm{~mm}$. Five different test configurations were considered for each bolt diameter.

A schematic view of a typical joint is presented in Fig. 2. The loaded side of the joint consisted of one FRP bolt centered across the width of the HFRP laminates. Meanwhile, the clamped side of the joint was formed using eight steel bolts with $6 \mathrm{~mm}$ diameter. The used steel bolts were made of high tensile steel of grade 8.8 with $375 \mathrm{MPa}$ shear strength and 1,000 $\mathrm{MPa}$ bearing strength. This number of high strength steel bolts was employed to ensure that no interfacial slippage would take place at the clamped side of the joint. All bolts were installed in standard size holes having diameters that are $2 \mathrm{~mm}$ bigger than those of the bolt shank. The FRP bolts and nuts were lubricated before being used in order to ease their movement as recommended in the manufacturer product sheet. The FRP nuts were tightened using a breaking type torque wrench to apply the recommended installation torque of $5.5 \mathrm{~N} . \mathrm{m}$ and $11 \mathrm{~N} . \mathrm{m}$ provided by the manufacturer for the $10 \mathrm{~mm}$ and $13 \mathrm{~mm}$ diameter bolts, respectively.

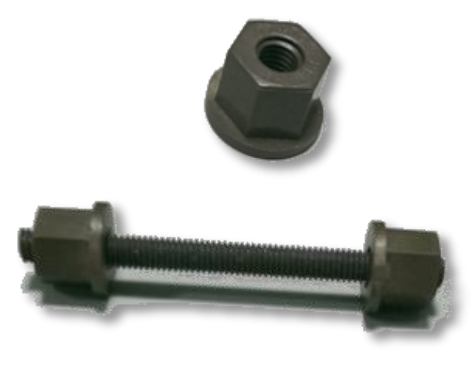

Fig. 1: Photo of the FRP bolt, washer and nut used in the experimental program.

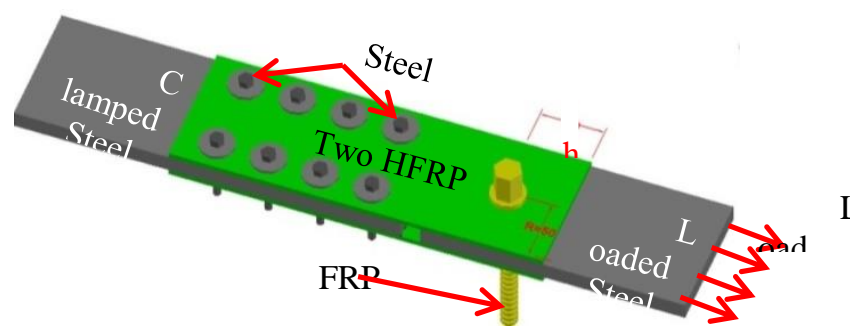

Fig. 2: Schematic view of a typical HFRP-steel joint using FRP bolts.

Analytical evaluation of the various failure modes expected to control the response of tested joints was conducted based on code requirements. The estimated strength values are summarized in Table 1 showing the possibility of FB10 joints to be governed by shear failure in FRP bolts while the response of FB13 joints is expected to be controlled by bearing in HFRP laminates.

Joints were subjected to axial tensile loading using a $100 \mathrm{kN}$ MTS Universal Testing Machine with a constant displacement rate of $1 \mathrm{~mm} / \mathrm{min}$. The longitudinal displacement of the joint was measured using two LVDTs at both sides of the specimen to account for any in-plane rotation during testing. The experimental setup of the HFRP-steel joints using FRP bolts is presented in Fig. 3. Each joint was instrumented with two strain gauges at the front and backsides of the joint to monitor the out-of-plane bending during testing. 
Table 1: Estimated strength of the possible failure modes of tested joints.

\begin{tabular}{|l|c|c|}
\hline Failure Mode & \multicolumn{2}{|c|}{ Strength (kN) } \\
\cline { 2 - 3 } & $\begin{array}{l}\text { FB10 } \\
\text { Bolt }\end{array}$ & $\begin{array}{c}\text { FB13 } \\
\text { Bolt }\end{array}$ \\
\hline Double shear failure in one FRP bolt & 14.7 & 23.3 \\
\hline Bearing of one bolt on a 10mm steel plate & 46.0 & 59.8 \\
\hline Bearing of one bolt on 6.35mm HFRP Laminates & 17.7 & 23.0 \\
\hline $\begin{array}{l}\text { Tensile fracture of the net area of 6.35mm HFRP } \\
\text { Laminates }\end{array}$ & 357.6 & 345.4 \\
\hline
\end{tabular}

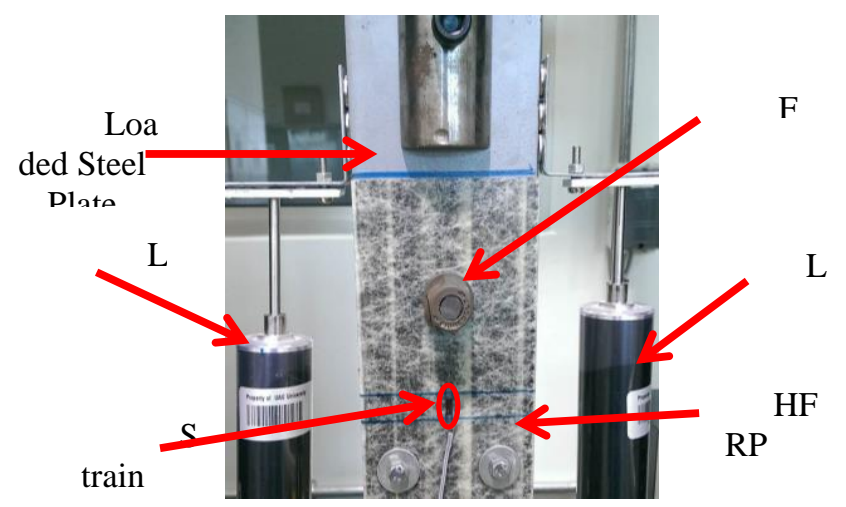

Fig. 3: The experimental setup of HFRP-steel joints using FRP.

For each bolt diameter, the examined sheared edge distances covered a wide range of two to six times the bolt-hole diameter. Table 2 displays the design values of the tested sheared edge distances using the $10 \mathrm{~mm}$ (FB10) and $13 \mathrm{~mm}$ (FB13) diameter bolts. Two specimens of each configuration were tested to ensure repeatability of the experimental results.

Table 2: Designed sheared edge distances for the FB10 and FB13 joints.

\begin{tabular}{|c|c|c|c|c|c|c|c|c|c|c|}
\hline Specimen Designation & \multicolumn{4}{|c|}{ FB10 } & \multicolumn{5}{|c|}{ FB13 } \\
\cline { 2 - 13 } & $\mathrm{D}$ & $\mathrm{D}$ & $\mathrm{D}$ & $\mathrm{D}$ & $\mathrm{D}$ & $\mathrm{D}$ & $\mathrm{D}$ & $\mathrm{D}$ & $\mathrm{D}$ & $\mathrm{D}$ \\
\hline $\begin{array}{c}\text { Sheared Edge Distance } \\
(\mathbf{m m})\end{array}$ & 4 & 6 & 8 & 0 & 2 & 0 & 5 & 0 & 5 & 0 \\
\hline
\end{tabular}

\section{Results and Discussions}

This section summarizes the main observations and outcomes related to the tensile tests that were conducted on the twenty bolted HFRP-steel joint specimens. Discussions of the obtained results are also outlined in the following subsections.

\subsection{Effect of Sheared Edge Distance}

The average load-displacement profiles of the FB10 joints showed close behavior as illustrated in Fig. 4. The obtained profiles revealed instantaneous increase in the load value with the application of the load until a displacement of $0.2 \mathrm{~mm}$ was attained. Following that, considerable increase in the displacement occurred (reaching a total displacement of about $2.5 \mathrm{~mm}$ ) with no apparent increase in the applied load. This flat segment of the response curve can be attributed to the relative slippage between the HFRP laminates and steel plates. Beyond the $2.5 \mathrm{~mm}$ displacement, the load value increased significantly in a linear manner until it reached a peak of $13 \pm 1 \mathrm{kN}$ at an average displacement value of about $7.5 \mathrm{~mm}$. This 
stage was characterized by noticeable bearing between the FB10 bolt and the HFRP laminates. Then, the excessive stresses induced in the FRP bolt caused its sudden failure by shear as depicted by Fig. 5. It is clear that changing the sheared edge distance from 2 to 6 times the hole-diameter using the FB10 had insignificant effect on the ductility of the joint as all joints experienced brittle failure once the peak load was reached. The experimental results revealed an increase in the ultimate load capacity of the joint with increasing the sheared edge distance (Sh) from twice to five times the bolt-hole diameter. Further increase of the sheared edge distance to six times the hole-diameter resulted in a reduction of the ultimate peak load from $14 \mathrm{kN}$ to $11 \mathrm{kN}$.

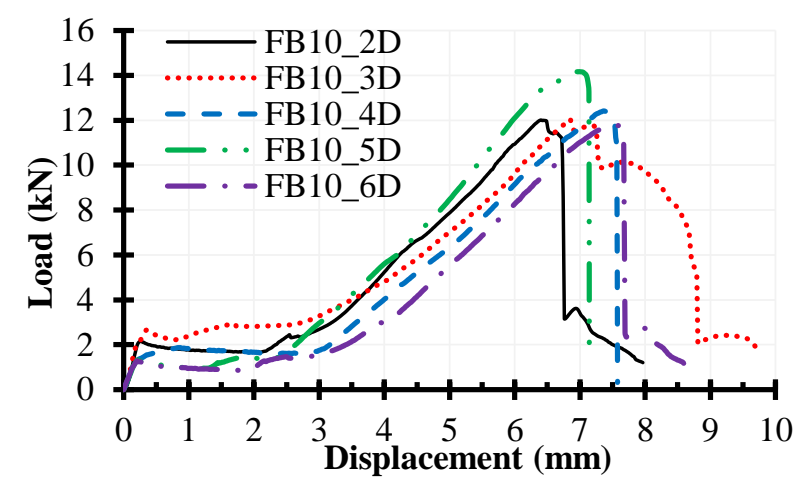

Fig. 4: Load-displacement curves for the fastened HFRPsteel joints using FB10 bolts.

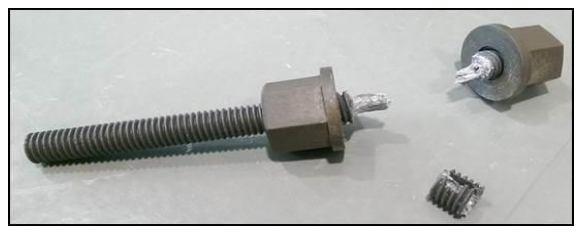

Fig. 5: Shear failure in FB10.

Figure 6 presents the average load-displacement response curves for the FB13 joints. All specimens with various sheared edge distance values showed a slight increase in the load value (around $3 \mathrm{kN}$ ) at a displacement of $0.2 \mathrm{~mm}$. After that, the load value remained constant until a displacement of $3 \mathrm{~mm}$ in a similar manner to the behavior of the FB10 joints. At this displacement value, the bearing action between the FB13 and the HFRP laminates started to take place causing a significant increase in the load value reaching a peak value that ranges between $19 \mathrm{kN}$ and $22 \mathrm{kN}$ at a displacement about 7 $\mathrm{mm}$. Once the peak load was attained, a gradual reduction in the load carrying capacity of the joints was observed followed by shear failure of the FB13 bolts.

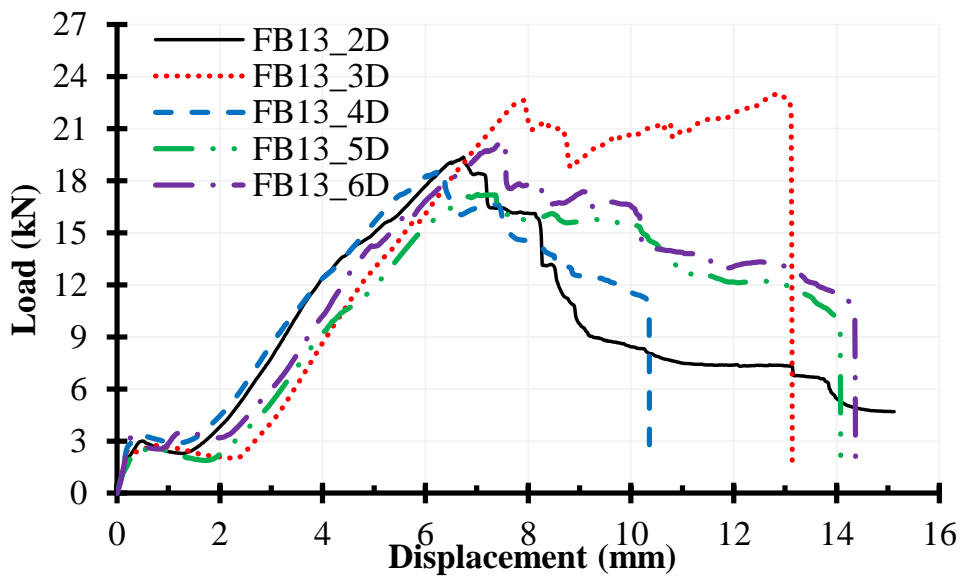

Fig. 6: Load-displacement curves for the fastened HFRP-steel joints using FB13 bolts.

ICSENM 103-5 
The peak load and post-peak behavior of the FB13 joints varied depending on the investigated sheared edge distance. For example, specimen FB13_2D experienced sudden drop in the load value at a displacement of $8 \mathrm{~mm}$ with a corresponding load of $15 \mathrm{kN}$. On the other hand, joint FB13_3D showed more ductile behavior as evident by the stable post-peak response corresponding to displacement value of $8 \mathrm{~mm}$ through $13 \mathrm{~mm}$. The failure load of the FB13_3D joint was $22 \mathrm{kN}$ at a displacement of $13 \mathrm{~mm}$.

Using a sheared edge distance that is greater than three times the bolt-hole diameter resulted in reduction in the peak load and joint ductility compared to those of the FB13_3D joints. No specific trend between the ultimate load carrying capacity of the joints and the different sheared edge distance can be observed from the plotted results.

Increasing the sheared edge distance (Sh) from two (2D) to three (3D) times the bolt-hole diameter enhanced the maximum load capacity of the joint from $18.5 \mathrm{kN}$ to $23 \mathrm{kN}$. However, using a (Sh) that is four times the bolt-hole diameter (4D) caused a reduction in the peak load of the joint. Further increase of the (Sh) from 4D to 6D resulted in a slight increase in the ultimate peak load of the joint by about $13 \%$ (from $19 \mathrm{kN}$ to $21.5 \mathrm{kN}$ ). The absence of a clear trend between the sheared edge distance and the peak loads could be attributed to the random rupture of the glass fibers constituting the material of FRP bolts. Based on the results obtained in the experimental program, the FB13_3D was selected as the configuration with the best performance in terms of both ultimate load and ductility response. It is important to highlight that the out-of-plane bending experienced by FB10 and FB13 joints was negligible as revealed by the close measurements recorded by front and backsides strain gauges for all tested joints. Representative strain measurements for joints FB10 and FB13 are shown in Figs. 7 and 8, respectively.

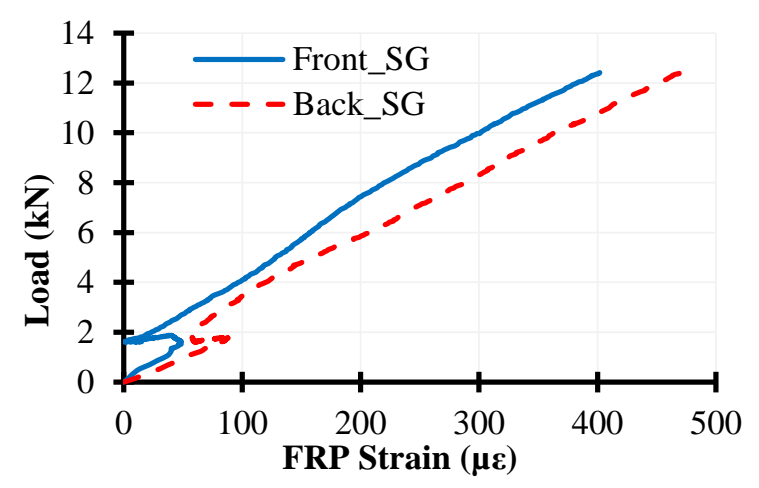

Fig. 7: Strain gauge measurements (joint FB10_4D).

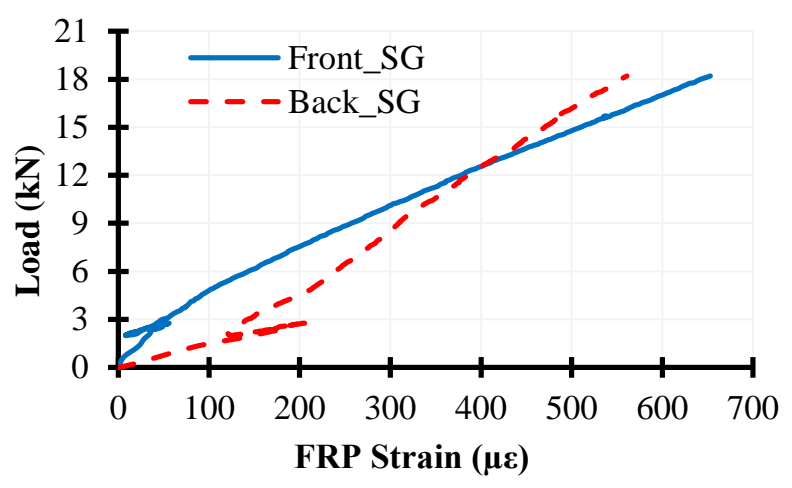

Fig. 8: Strain gauge measurements (joint FB13_3D).

\subsection{Effect of Bolt Diameter}


Comparison between the average peak load of all FB10 specimens (Fig. 4) and that of the FB13 specimens (Fig. 6) shows about $65 \%$ enhancement in the ultimate load carrying capacity of the joints associated with the $3 \mathrm{~mm}$ increase in the bolt diameter. For the proposed optimum sheared edge distance of three times the bolt-hole diameter (3D), the recorded peak load of the FB10 was $12 \mathrm{kN}$, while its counterpart value for FB13 was $23 \mathrm{kN}$ indicating 91.5\% improvement in the load carrying capacity of the joint. Furthermore, comparing the load-displacement curve of FB13_3D shown in Fig. 6 and that of FB10_3D (see Fig. 4) reveals considerable enhancement in the ductility of the HFRP-steel joint with $13 \mathrm{~mm}$ diameter bolt. Similar ductility enhancement can be noticed for all other joints formed using $13 \mathrm{~mm}$ diameter bolts (Fig. 6) compared to their counterparts with $10 \mathrm{~mm}$ bolts (Fig. 4).

\subsection{Load-slip Model}

As discussed in section 3.1, the FB13_3D configuration, for joints with $13 \mathrm{~mm}$ FRP bolt and sheared edge distance of three times the bolt-hole diameter, was recommended for optimal performance of this particular type of HFRP-steel joints. As such, the experimental response curve of this configuration was used to develop an idealized load-slip model as presented in Fig. 9. Noting that the experimental load-displacement curve of FB13_3D (Fig. 6) corresponds to the response of one FB13 bearing against two HFRP laminates; the load values were adjusted to represent a single-shear setup. The various segments constituting the proposed model corresponded to five different failure modes of the HFRP-steel joint (refer to Fig. 9). Segment "A" represents the friction between the HFRP laminates and the steel plates, while segment "B" relates to the relative slippage arising from the bolt-hole clearance. Bearing action between the bolt and HFRP laminates is reflected by segment "C". Part " $D$ " represents the combined effect of bearing and bending in bolts. Finally, the ultimate shear failure of the joint is demonstrated by the descending segment " $E$ ".

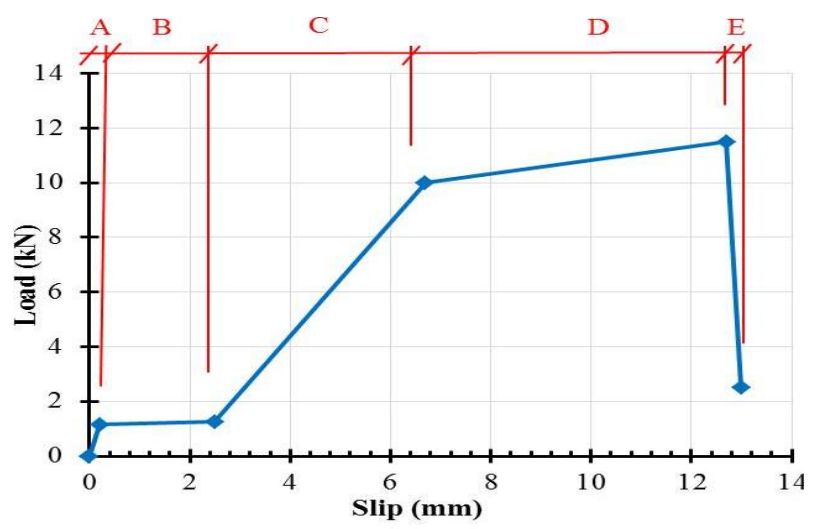

Fig. 9: Nonlinear load-slip model of the FB13_3D joint.

\subsection{Effect of Bolt Type}

In order to evaluate the effectiveness of using FRP bolts as compared to the commonly used steel bolts in forming HFRP-steel strengthening systems, a comparison was conducted between the proposed load-slip model in Fig. 9 and the load-slip model shown in Fig. 10 for a similar joint that uses $6 \mathrm{~mm}$ diameter galvanized steel bolts [6]. From strength standpoint, joints bolted using FB13 showed load carrying capacity that is $15 \%$ higher than that for the steel bolted joints (11.5 kN for FB13_3D and $10 \mathrm{kN}$ for steel bolted joint in single shear plane per bolt).

As evident by Figs. 9 and 10, the load-slip model of the joints with steel bolts exhibited slightly more ductile response compared to those with FRP bolts (the ultimate failure of FB_3D joint occurred at displacement of $13 \mathrm{~mm}$, while for joints with steel bolts it took place at $16.5 \mathrm{~mm}$ ). It should be noted that attaining the reported increase in the strength of the joint with FRP bolts (i.e., 15\%) required the utilization of FRP bolts with double the diameter of their steel counterparts. This is directly reflected on the size of holes to be drilled in the connected elements, which could reduce the ultimate tensile strength of such elements. Aside from that, the use of FRP bolts provides good alternative to overcome the potential corrosion of steel due to their corrosion resistivity, lightweight and high strength-to-weight ratio. 


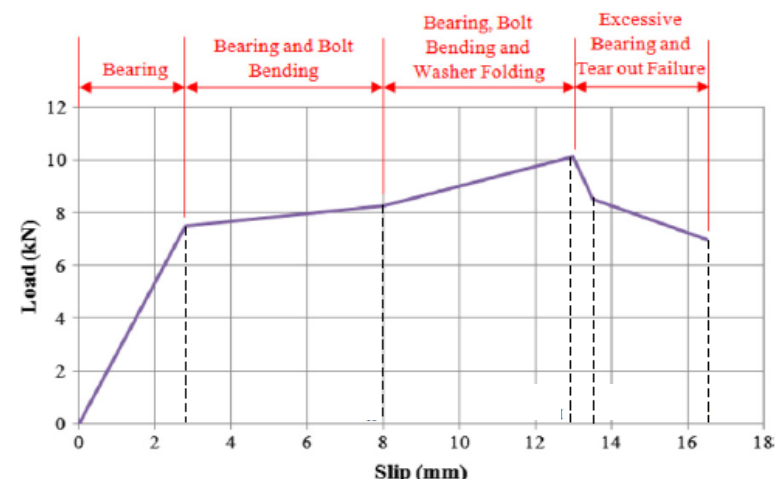

Fig. 10: Nonlinear load-slip model of the HFRP-steel joint fastened using steel bolts.

\section{Conclusion}

An experimental study was conducted to explore the structural behavior of HFRP-steel joints with FRP bolts. A total of twenty double-lap HFRP-steel joints with two different bolt diameters and several sheared edge distances were subjected to axial tensile loading. All tested joints failed mainly by bearing between the FRP bolts and the HFRP laminate followed by post peak shear rupture of the FRP bolts. Experimental findings revealed negligible effect of the considered sheared edge distances on the response of HFRP-steel joints for both tested bolt diameters. The load carrying capacity of the tested joints was significantly enhanced by $65 \%$ with increasing the FRP bolt diameter from $10 \mathrm{~mm}$ to $13 \mathrm{~mm}$. Joint bolted using FRP bolt of $13 \mathrm{~mm}$ diameter with sheared edge distance that is three times the bolt-hole diameter showed the optimal performance in terms of both ultimate load and ductility among all tested joints. The experimental response of the optimal configuration was used to develop a simplified nonlinear load-slip model to characterize the interfacial behavior of the joints formed using FRP bolts. Developed model was compared to a previously published load-slip model for HFRPsteel joint that uses steel bolts. The comparison showed an enhancement of $15 \%$ in the load capacity of the joint with FRP bolt of $13 \mathrm{~mm}$ diameter compared to the steel bolted joint with a lower displacement at failure.

\section{Acknowledgements}

The authors would like to acknowledge the financial support provided by the College of Engineering at UAEU. They would like also to acknowledge the support of Al Fara'a Steel Structures in manufacturing the steel elements and drilling of all components of the tested joints.

\section{References}

[1] J. W. Gillespie, D. R. Mertz, , W. M. Edberg, J. R. Demitz, K. Kasai and I. Hodgson, "Rehabilitation of steel bridge girders: large scale testing," in Proceedings of the American Society for Composites, Eleventh Technical Conference, Atlanta, GA, 1996, pp. 231-240.

[2] R. Sen, L. Liby and G. Mullins, "Strengthening steel bridge sections using CFRP laminates," Composites Part B: Engineering, vol. 32, no. 4, pp. 309-322, 2001.

[3] A. Lenwari, T. Thepchatri and P. Albrecht, "Flexural response of steel beams strengthened with partial-length CFRP plates," Journal of Composites for Construction, vol. 9, no. 4, pp. 296-303, 2005.

[4] O. Buyukozturk, O. Gunes and E. Karaca, "Progress on understanding debonding problems in reinforced concrete and steel members strengthened using FRP composites," Construction and Building Materials, vol. 18, no. 1, pp. 919, 2004.

[5] N. D. Hai and H. Mutsuyoshi, "Structural behavior of double-lap joints of steel splice plates bolted/bonded to pultruded hybrid CFRP/GFRP laminates," Construction and Building Materials, vol. 30, pp. 347-359, 2012.

[6] A. M. Sweedan, M. M. Alhadid and K. M. El-Sawy, "Experimental study of the flexural response of steel beams strengthened with anchored hybrid composites," Thin-Walled Structures, vol. 99, PP. 1-11, 2016. 
[7] A. M. Sweedan, K. M. El-Sawy and M. M. Alhadid, "Interfacial behavior of mechanically anchored FRP laminates for strengthening steel beams," Journal of Constructional Steel Research, vol. 80, pp. 332-345, 2013.

[8] A. M. Sweedan, H. N. Rojob and K. M. El-Sawy, "Mechanically-fastened hybrid composites for flexural strengthening of steel beams," Thin-Walled Structures, vol. 85, pp. 250-261, 2014.

[9] M. A. Erki, "Bolted glass-fibre-reinforced plastic joints," Canadian Journal of Civil Engineering, vol. 22, no. 4, pp. 736-744, 1995.

[10] R. Starikov and J. Schön, J. "Quasi-static behaviour of composite joints with countersunk composite and metal fasteners," Composites Part B: Engineering, vol. 32, no. 5, pp. 401-411, 2001.

[11] R. Starikov and J. Schön, "Fatigue resistance of composite joints with countersunk composite and metal fasteners," International Journal of Fatigue, vol. 24, no. 1, pp. 39-47, 2001. 